\title{
Knowledge and Practice of Antenatal care Attendant Mothers Towards Iodized Salt Utilization and Associated Factors in Ambo Town Public Health Facilities, Oromia, Ethiopia
}

\author{
Dereje Bayissa Demissie*, Chala Beka, Kebede Chala, Fenet Biru, Gadise Lelisa and Bizu Beyu \\ Department of Nursing and Midwifery, Ambo University, Ethiopia
}

Submission: November 07, 2017; Published: November 30, 2018

*Corresponding author: Dereje Bayissa Demissie, College of Medicine and Health Sciences, Department of Nursing and Midwifery, Ambo University, Ethiopia

\begin{abstract}
Background: Globally iodized salt deficiency affects more than 2.2 billion peoples and the effect is severe when occurs in pregnant women. Different reasons contribute for insufficient iodized salt utilization in population. Even though knowledge and practice of iodized salt utilization has paramount contribution in improving iodized salt utilization among pregnant mothers. To assess the knowledge and practice of iodized salt utilization and associated factors among ANC follower pregnant women at Public Health Facilities, Ambo Town.

Results: The complete response rate of the study was $240(93.02 \%)$. Almost all of $97.1 \%$ are Oromo in Ethnicity and 53.8\% were housewives and only $29.6 \%$ were attending college and university in Educational status. This study determined knowledge and practice of pregnant women towards iodized salt utilization which revealed that $65.6 \%$ have had good knowledge towards iodized salt utilization with factors educational level, ever heard iodized salt and occupation were significantly associated with knowledge of mothers about iodized salt utilization. Out of total study respondents $3 / 4^{\text {th }}$ of pregnant women had good practice of Iodized salt utilization with independent predictor of family income, being educated and occupation status respectively.

Methods: Institution based cross sectional study design was employed on total of 240 pregnant women was enrolled in the study. Data were collected using interviewer administered questionnaire and was entered and analyzed using statistical package for social science version 20. Binary and multiple logistic regression analysis were carried utilized to identify significant association at p-value of less than 0.05 that was considered as significant association.

Conclusion: This study determined knowledge and practice of pregnant women towards iodized salt utilization which revealed low and high compared to previous studies respectively. This study identified that factors contributed to knowledge and practice of pregnant women towards iodized salt utilization. Therefore, police makers and health planner would be better to reconsider these factors affecting iodized salt utilization practice and knowledge pregnant mothers while developing guidelines and Health education programs for this population.
\end{abstract}

Keywords: Lodized; Salt; Deficiency; Pregnant women; Hearing defects; Brain; Thyroid hormone; Euthyroid state

\section{Background}

Maternal iodine deficiency results in a range of intellectual, motor and hearing defects in their off springs but it is very damaging. when the deficiency of iodine happens during pregnancy because it retards all fetal development especially the development of brain. This loss of intellectual capacity limits educational achievement of population and economic power of nation $[1,2]$.

More importantly this iodine deficiency during pregnancy is intergenerational and its effect can continue throughout the generation since its deficiency greatly affect the level of IQ and on the hand during pregnancy the need for iodized salt is raised due to three main reasons those are an increase in the production of thyroxin (T4) by the mother to maintain her euthyroid state and transfer thyroid hormone to the fetus and the transfer of iodine to the fetus, particularly in the late gestation and 3 , an increase in renal iodine clearance (RIC) by the mother and greatly plays role on the future intellectuality of the baby [3].

In order to reduce and eliminate multi aspect of the problem associated with the insufficient iodized salt consumption; WHO and UNICEF jointly prepare universal salt iodization (USI) strangely in 1994 and WHO proposed the national iodized salt consumption guidelines including that of pregnant mothers and lactating mothers.

All those threats are aimed to improve attitude knowledge and practice of global nations towards iodized salt consumption and to abolish those evil problems which occurs due to lack of 


\section{Journal of Gynecology and Women's Health}

insufficiency of iodized salt consumption [4]. During pregnancy, iodine deficiency is extremely damaging because it retards fetal physical and mental development. Reports show that there is enormous loss of humor intellectual physical and social potentials due to iodine deficiency worldwide [5]. This indicates that; the iodine deficiency during pregnancy is intergenerational problems [6]. Universal salt iodization (USI) strategy is considered as the main strategy in reduction and elimination of iodine deficiency associated problems and Ethiopian government also adopt this strategy and trying to access iodized salt for communities with cost effective price but the problem still continued to be public health issue in the country $[7,8]$. Despite few local studies conducted in certain part of the country, no significant studies performed in the selected area and even in the country. So, this study would identify and believe on the need of research to know and coped up with problems related to the knowledge \&practice and associated factors on iodized salt utilization of pregnant mothers in the study area.

Result

\section{Socio demographic characteristic of the respondent}

Out of the total of 240 pregnant women ANC attendants the majority $91.9 \%$ of the respondents were in age group of 18-30 years with mean value of 24.89 years, which ranges from 18 and 38years (Figure 1). The respondents were married and almost all of $97.1 \%$ were Oromo in Ethnicity and $53.8 \%$ were housewives. From the total of 240 pregnant women who had college and university level were $29.6 \%$ (Table 1-4).

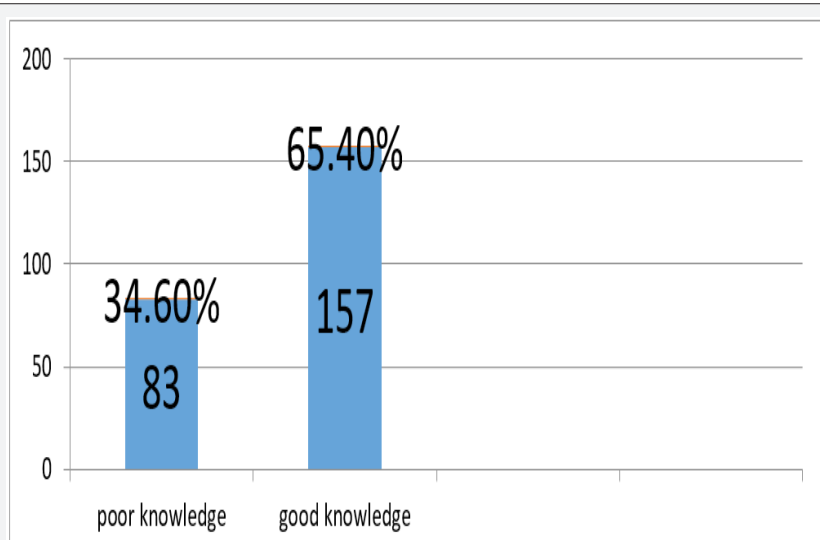

Figure 1: Knowledge of lodized salt utilization distribution by percent among pregnant women attending ANC at public health facilities in Ambo Town 2017.

Table 1: Socio demographic characteristics of pregnant women attending ANC at Ambo Town Public Health Facilities, Oromia, Ethiopia, 2017

\begin{tabular}{|c|c|c|c|}
\hline S. No & Age of Respondent & Frequency & Percent \\
\hline \multirow[t]{3}{*}{1} & $18-20$ & 47 & 19.6 \\
\hline & $21-30$ & 173 & 2.1 \\
\hline & $>30$ & 20 & 8.3 \\
\hline \multirow[t]{4}{*}{2} & \multicolumn{3}{|c|}{ Ethnicity } \\
\hline & Oromo & 233 & 97.1 \\
\hline & Amhara & 5 & 2.1 \\
\hline & Tigre & 2 & 0.8 \\
\hline \multirow[t]{3}{*}{3} & \multicolumn{3}{|c|}{ Place of Residence } \\
\hline & Urban & 211 & 87.9 \\
\hline & Rural & 29 & 12.1 \\
\hline \multirow[t]{6}{*}{4} & \multicolumn{3}{|c|}{ Educational Status } \\
\hline & Illiterate & 31 & 12.9 \\
\hline & Read and write & 31 & 12.9 \\
\hline & Elementary school & 58 & 24.2 \\
\hline & secondary school & 49 & 20.4 \\
\hline & college and above & 71 & 29.6 \\
\hline \multirow[t]{3}{*}{5} & \multicolumn{3}{|c|}{ Occupation of husband } \\
\hline & Government employee & 86 & 35.8 \\
\hline & Farmer & 30 & 12.5 \\
\hline
\end{tabular}




\section{Journal of Gynecology and Women's Health}

\begin{tabular}{|c|c|c|c|}
\hline & Merchant/labour & 124 & 51.7 \\
\hline $\mathbf{6}$ & \multicolumn{2}{|c|}{ Family Size } & 34.6 \\
\hline & $<2$ & 83 & 55.4 \\
\hline $\mathbf{7}$ & $3-5$ & 133 & 10 \\
\hline & $>6$ & 24 & 30.4 \\
\hline & \multicolumn{2}{|c|}{ Monthly Income } & 21.3 \\
\hline & $1001-2000$ & 51 & 43 \\
\hline
\end{tabular}

Table 2: Knowledge of ANC attending pregnant women about iodized salt utilization at Ambo town public health facilities, Ambo town, Oromia, Ethiopia 2017

\begin{tabular}{|c|c|c|}
\hline Variable & Frequency & Percentage \\
\hline \multicolumn{3}{|l|}{ Ever Heard about Iodized Salt } \\
\hline Respondents who was heard about iodized salt & 196 & $81.70 \%$ \\
\hline \multicolumn{3}{|l|}{ Lists of Heard Place } \\
\hline 1 media & 112 & $46.70 \%$ \\
\hline 2 friends & 73 & $30.40 \%$ \\
\hline 3 health workers & 11 & $4.60 \%$ \\
\hline Respondents who said every salt contain iodine & 39 & $16.30 \%$ \\
\hline Respondents who Ever Heard the Importance of Iodized Salt Consumption During Pregnancy & 136 & $56.70 \%$ \\
\hline 1 to prevent maternal goitre & 76 & $31.70 \%$ \\
\hline 2 to maintain healthy physical and mental growth & 60 & $25.40 \%$ \\
\hline \multicolumn{3}{|l|}{ Storage of Iodized Salt at Home } \\
\hline Respondents who known storage of iodine at home & 172 & $71.70 \%$ \\
\hline \multicolumn{3}{|l|}{ Place of Storage } \\
\hline 1 in closed container away from sunlight & 168 & $70 \%$ \\
\hline 2 in open container & 4 & $1.70 \%$ \\
\hline The Right Time to Add Iodized Salt to Meal & 178 & $74.20 \%$ \\
\hline At beginning & 52 & $29.20 \%$ \\
\hline At end & 126 & $70.80 \%$ \\
\hline
\end{tabular}

Table 3: Factors association with knowledge between of iodized salt utilization at multivariable logistic regression at Ambo town public health facilities of ANC follower's pregnant mothers, Ethiopia 2017

\begin{tabular}{|c|c|c|c|c|c|c|c|c|}
\hline \multirow{2}{*}{ S. No } & \multirow{2}{*}{ Variable } & & \multicolumn{2}{|c|}{ Knowledge n (\%) } & \multirow{2}{*}{ p-Value } & \multirow{2}{*}{ AOR } & \multirow{2}{*}{\multicolumn{2}{|c|}{$95 \%$ CI }} \\
\hline & & & Good & Poor & & & & \\
\hline \multirow{2}{*}{1} & \multirow{2}{*}{$\begin{array}{l}\text { Ever Heard Iodized } \\
\text { Salt }\end{array}$} & Yes & $172(71.7 \%)$ & $24(10 \%)$ & 1.000 & 33.433 & 10.214 & 109.4 \\
\hline & & No & $6(2.5 \%)$ & $62(25.8 \%)$ & 1.000 & & & \\
\hline \multirow{4}{*}{2} & \multirow{4}{*}{ Occupation } & Housewife & $90(37.5 \%)$ & $-16.20 \%$ & 0.067 & 6.941 & 0.876 & 54.972 \\
\hline & & Gov't Employ & $39(16.2 \%)$ & $5(2.1 \%)$ & 0.026 & 11.1 & 1.33 & 92.915 \\
\hline & & Farmer & $46(19.2 \%)$ & $17(7.1 \%)$ & 0.016 & 13.857 & 1.638 & 117.24 \\
\hline & & Daily/Merchant & $3(1.2 \%)$ & $34(14.2 \%)$ & 1.000 & & & \\
\hline \multirow{5}{*}{3} & \multirow{5}{*}{ Educational Status } & Illiterate & $14(5.8 \%)$ & $17(7.1 \%)$ & 0.018 & 0.182 & 0.045 & 0.742 \\
\hline & & Read and Write & $23(9.6 \%)$ & $8(3.3 \%)$ & 0.027 & 0.236 & 0.066 & 0.848 \\
\hline & & Primary School & $43(17.9 \%)$ & $15(6.2 \%)$ & 0.012 & 0.213 & 0.064 & 0.71 \\
\hline & & Secondary School & $35(14.6 \%)$ & $145.8(\%)$ & 0.003 & 0.168 & 0.015 & 0.551 \\
\hline & & College and Above & $63(26.2 \%)$ & $8(3.3 \%)$ & 1.000 & & & \\
\hline
\end{tabular}


Table 4: Factors association between practiced iodized salt utilization in Ambo town public health facilities of ANC follower's pregnant mothers, Ethiopia 2017

\begin{tabular}{|c|c|c|c|c|c|c|c|c|}
\hline \multirow{2}{*}{ S. No } & \multirow{2}{*}{ Variable } & \multirow{2}{*}{ Category } & \multicolumn{2}{|c|}{ Practice $n(\%)$} & \multirow{2}{*}{ p-value } & \multirow{2}{*}{ AOR } & \multirow{2}{*}{\multicolumn{2}{|c|}{$95 \%$ CI }} \\
\hline & & & Good & Poor & & & & \\
\hline \multirow{3}{*}{1} & \multirow{3}{*}{ Family Income } & $<1000$ & $60(25 \%)$ & $23(9.6 \%)$ & $1: 00$ & & & \\
\hline & & $1001-2000$ & $107(44.6 \%)$ & $26(10.8 \%)$ & 0.058 & 2.334 & 0.973 & 5.6 \\
\hline & & $>2001$ & $11(4.6 \%)$ & $13(5.4 \%)$ & 0.011 & 2.837 & 1.26 & 6.36 \\
\hline \multirow{4}{*}{2} & \multirow{4}{*}{ Occupation } & Housewife & $90(37.5 \%)$ & $-16.20 \%$ & 0.023 & 8.28 & 1.34 & 51.01 \\
\hline & & Gov't Employee & $39(16.2 \%)$ & $5(2.1 \%)$ & 0.02 & 9.825 & 1.43 & 67.59 \\
\hline & & Farmer & $46(19.2 \%)$ & $17(7.1 \%)$ & 0.011 & 11.25 & 1.73 & 73.15 \\
\hline & & Daily/Merchant & $3(1.2 \%)$ & $34(14.2 \%)$ & 1.000 & & & \\
\hline \multirow{5}{*}{3} & \multirow{5}{*}{ Educational Status } & Illiterate & $4(5.8 \%)$ & $17(7.1 \%)$ & $1: 00$ & & & \\
\hline & & Read and Write & $23(9.6 \%)$ & $8(3.3 \%)$ & 0.111 & 2.55 & 0.805 & 8.071 \\
\hline & & Primary School & $43(17.9 \%)$ & $15(6.2 \%)$ & 0.033 & 2.8 & 1.08 & 7.41 \\
\hline & & Secondary School & $35(14.6 \%)$ & $145.8(\%)$ & 0.018 & 1.9 & 1.72 & 5.43 \\
\hline & & College and Above & $63(26.2 \%)$ & $8(3.3 \%)$ & 0.01 & 6.4 & 1.86 & 22.2 \\
\hline
\end{tabular}

From the total of 240 respondents, most of them have family size of 3-5 were 133 (55.4\%) with mean value of their family size were 3.4 , which ranges from 1 and 11 family size. From the total of 240 pregnant women, $116(48.3 \%)$ were had family monthly income of greater than 2001, Ethiopian birr with Average income was 3573.125 which ranges from 300 and 25000 Ethiopian birr.
Out of 240 ANC attendants, the majority of them were in third trimester 92 (38.3\%) within mean value of 2.53 which ranges from 1 and 3 trimester. From the total respondents 177 (73.8\%) had 1-2, pregnancies and from the number of pregnancy of respondents the mean value was 2.125 of 1 and 7 were minimum and maximum respectively (Figure 2).

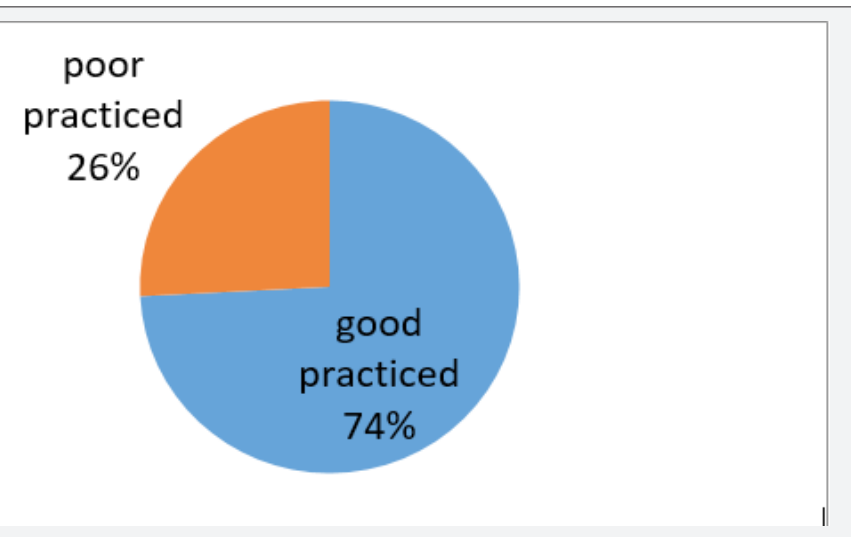

Figure 2: Practice of lodized salt utilization distribution among pregnant women attending ANC at public health facilities in Ambo Town 2017.

Majority of respondents had 0-1 deliveries which was 179 $(74.6 \%)$ and from the number of deliveries of respondents the mean value was1.07 which ranges from 0 and 6 deliveries.From 240 respondents, 8 had history of still birth from those 6 of them had 1 still birth and 23 of them had at least one history of abortion.

The majority of the respondents, $68(28.3 \%)$, were on their third visits, most of them began ANC visit $178(74.2 .1 \%)$ at $13-25$ weeks.

\section{Results on knowledge of iodized salt utilization}

Regarding to the importance of iodized salt consumption during pregnancy; about $43.3 \%$ of the respondents were didn't know. From total the respondents about $81.7 \%$ were ever heard about iodized salt of which mentioned that they heard about iodized salt $46.7 \%$ of them heard by media which is followed it from health worker $4.6 \%$ and friends $30.4 \%$. Regarding to this study of every salt contain iodine most of the respondents, $83.8 \%$ of them said no and $16.3 \%$ of them said yes. From those respondents who mentioned they know about iodized salt; most of them choose (42.9\%) didn't know followed by maternal goiter (31.7\%) and healthy fetal physical and mental growth (25.4\%). Majority of our respondents $28.3 \%$ didn't know how to store iodized salt and from those who said that they know $70 \%$ store it in closed container away from sunlight and don't know 28.8\%.

From the problem caused by iodine deficiency of the respondents $42.1 \%$ didn't know any health problem caused by iodine deficiency. Even from those who mentioned that they knew about it most of them knew only about goiter (45.8\%). therefore, the majority of respondents were responded problem caused by iodine deficiency was $45.8 \%$ goiter caused by iodine deficiency. Knowledge on the main source of iodine in food consumed by 
pregnant women in Ambo Town a higher percentage of the respondents $48 \%$ said that drink water the major source. This study determined knowledge of pregnant women towards iodized salt utilization which revealed that $157(65.6 \%$ with $95 \%$ CI $(60-$ $71.3 \%$ ) were had good knowledge/ knowledgeable towards iodized salt utilization.

\section{Factors associated with knowledge of pregnant women towards Iodized salt utilization at multivariable logistic regression}

Pregnant women who ever heard about Iodized salt utilization were 33.43 times 95\% CI (10.21-109.42). more likely to have been knowledgeable as compared to had not ever heard women. Pregnant women whose occupational status of government and farmers were 11.1 times 95\%CI [(1.33-92.91) and 13.86 times (1.64-117.24)] more likely to have been knowledgeable as compared to daily labor/march respectively.

Pregnant mothers who have no formal education were 0.182 times (0.045- 0.742), able to read and write 0.24times $(0.066$ -0.85), being attend primary school 0.21 times $(0.064-0.71)$ and secondary school 0.17 times $(0.051-0.55)$ less likely to have been knowledgeable as compared to attended College and above study participants.

\section{Practiced of utilization of iodized salt}

Regarding to the question about the right timing to add iodized salt to meal $25.8 \%$ of the respondents $74.2 \%$ knew about it. From those who mentioned that they know $70.8 \%$ said that at the end of cooking and $29.2 \%$ at the beginning of cooking. This study identified that out of total study respondents $3 / 4^{\text {th }}$ pregnant women had good practice of Iodized salt utilization with $95 \% \mathrm{CI}$ $178(74.2 \%$ (68.8-79.6\%).

\section{Factors associated with practiced of pregnant women towards Iodized salt utilization at multivariable logistic regression}

Pregnant women's family monthly income of 1001-2000 Ethiopian birr was 2.33 times 95\%CI (0.975-5.6) and their monthly income greater than 2001 was 2.83 times $95 \% \mathrm{CI}$ (1.265- 6.36) more likely to have been practiced as compared to whose family monthly had less than 1000 Ethiopian birr .Pregnant women whose occupational status of being house wife, government and farmers were 8.285 times 95\%CI [(1.345- 51.01), 9.825 times (1.428- 67.59)] and 11.25 times 95\%CI (1.73-73.15) more likely to have been practiced as compared to daily labor/ march respectively. Pregnant mothers whose educational status of attend primary school 2.83times95\%CI (1.08 -7.4), secondary school were 1.97 times 95\%CI (.717-5.43) and attended College and above were 6.42 times $95 \% \mathrm{CI}(1.86-22.15)$ more likely to have been practiced as compared to Illiterates.

\section{Discussion}

Ethiopia is among those countries greatly affected with iodine deficiency disorders and the problem is persists as public health problem until now.
The study which is conducted among hyperthyroidism patients in South Africa indicates that majority of the patients didn't know what iodine is (86.9\%) [8]. Even those who mentioned that they know what it is $(14.1 \%)$ were not clear because $4.9 \%$ indicated that its vitamin while $4.9 \%$ indicated that it is mineral. On this study of participant; $18.3 \%$ indicated that they didn't know what iodized salt is, and on importance of iodized salt consumption during pregnancy, about $43.3 \%$ of the respondent didn't know. This discrepancy may be due to that study population of the research done in South Africa were less than this study, because it was done on hyperthyroidism patients whose may be less than the study population of this study, and the sociodemographic characteristics of the people in the two area may have also its own contribution for the difference of the value.

The current study reveals that $20 \%$ of house hold were used iodized salt, which is higher than that of Sudan $14.4 \%$. This difference may be due to the effort of Ethiopian government to access the iodized salt for the people of the country [9]. Currently this finding $74 \%$ higher house hold used iodized salt utilization, and this may be due to the effort of health worker to given health education about iodized salt utilization for the ambo town households.

In this study proper period for addition of iodized salt to meal, $29 \%$ didn't know proper (preferable) time of adding iodize salt to their meal. $48.8 \%$ of the respondent mention that they didn't know single source of iodine. Even though, this study shows slightly greater person used iodized salt in their home than that of research done on Sudanese still there is a gap on using iodized salts. The discrepancy may be due that this research was based on ANC followers' pregnant women.

The respondents who were illiterate and can only read and write were less likely know about iodized salt utilization compared to that complete elementary school. Regarding the proper period for addition of iodized salt to meal, from of them 25.8\% didn't know proper (preferable) time of adding iodize salt to their meal.

Monthly income of the respondent was highly associated with knowledge of pregnant mothers on iodized salt utilization. Respondents who Ethiopian birr got 1000-2000 per month were more likely knows about iodized salt utilization as compared to those who earn less than 1000 birr per month.

\section{Conclusion}

This study determined knowledge and practice of pregnant women towards iodized salt utilization which revealed low and high compared to previous studies respectively. This study identified that factors contributed to knowledge and practice of pregnant women towards iodized salt utilization. Out of 240 of the pregnant mothers enrolled in the study responds $18.3 \%$ didn't know about iodized salt utilization and $43.3 \%$ of the participant report they didn't know the importance of iodized salt utilization during pregnancies.

Therefore, police makers and health planner would be better to reconsider these factors affecting iodized salt utilization prac- 
tice and knowledge pregnant mothers while developing guidelines and Health education programs for this population.

Finding of this study indicates that factors such as ever heard iodine salt, occupation of respondents, Academic achievement and monthly income, occupation of respondents, Academic achievement highly associated with knowledge level and the practiced of pregnant mothers enrolled in the study respectively. The study participant from the urban, able to read and right and those who have $>2001$ Ethiopian birr were more likely to know about importance of iodized salt utilization during pregnancy. In addition to factors mentioned above, there is no enough information available to develop community knowledge on the importance of iodized salt utilization.

Therefore, police makers and health planner would be better to reconsider these factors affecting iodized salt utilization practice and knowledge pregnant mothers while developing guidelines and Health education programs for this population. The Ambo town administration and health office collaborate to create awareness in the community on iodized salt consumption and effect of iodine deficiency.

The Ambo town public health facilities staffs would be better to strengthen health education for ANC attendants about the importance of using iodized salt during pregnancy, how to store and right timing to add while cooking.

\section{Authors' Contribution}

Dereje Bayissa, Chala Beka, Kebede Chala, Fenet Biru, Gadise Lelisa \& Bizu Beyu conceptualized the study, designed the study instrument and conducted the data analysis and wrote the first draft and final draft of the manuscript. Dereje Bayissa Demissie: Approved the research proposal with some revisions, participated in data analysis, revised subsequent drafts of the paper and involve in critical review of the manuscript. All authors read and approved the final manuscript.

\section{Acknowledgement}

The authors are grateful to Ambo University College of health sciences department of Nursing for providing the opportunity to conduct this research proposal. We would like to thank the study participants and Public health facilities (General Ambo Hospital, Ambo health center and Awaro health center administrative) for their very important cooperation.

\section{References}

1. Politidimitra (2009) The impact of iodine deficiency. BA Athens University of economics and business.

2. Maberly GF, Haxton DP, Van der Haar F (2003) Iodine deficiency: consequences and progress toward elimination. Food Nutr Bull 24(4 Suppl): S91-98.

3. Zimmermann BM (2007) The impact of iodine salt or iodine supplements on iodine status during pregnancy, lactation and infancy. Public Health Nutr 10(12A):1584-1595.

4. (2013) Worldwide Iodine deficiency disorder. Iodine deficiency disorder newsletter, WHO.

5. Glinoer Daniel (2007) The importance of iodine nutrition during pregnancy. Public Health Nut 10(12A):1542-1546.

6. Dugasa Begna (2013) Iodine deficiency and human heath: colonialism's malign effect on health in Oromia region, in Ethiopia.

7. Tamene Fite Duressa, Ahmed Yasin Mohammed, Girma Regassa Feyissa, Lemma Teshome Tufa, Khalid Siraj (2014) Comparative analysis of iodine concentration in water, soil, cereals and Tablet salt of Horaboka, Mio and Besaso towns of Bale Robe, South East Ethiopia. Environmental pollution and Human Health 2(1).

8. MLD Sebotsa, A Dannhausir, WF Mollentze, GM Oosthuizen (2009) Knowledge, Attitude and practices regarding Iodine among patients with in hyper thyroidism in the Free State. South Africa Clin Nutr 22(1).

9. Mahfouz MS, Gaffar AM, Bani IA (2012) Iodized salt consumption in Sudan: present status and future directions. J Health Popul Nutr 30(4): 431-438.

\begin{tabular}{l} 
Your next submission with Juniper Publishers \\
will reach you the below assets \\
- Quality Editorial service \\
- Swift Peer Review \\
- Reprints availability \\
- E-prints Service \\
- Manuscript Podcast for convenient understanding \\
- Global attainment for your research \\
- Manuscript accessibility in different formats \\
( Pdf, E-pub, Full Text, Audio) \\
- Unceasing customer service \\
Track the below URL for one-step submission \\
https://juniperpublishers.com/online-submission.php \\
\hline
\end{tabular}

